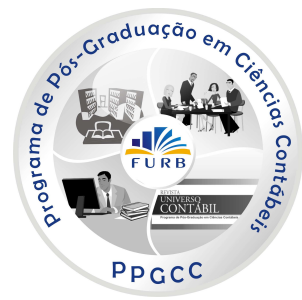

LUCRO LÍQUIDO VERSUS LUCRO ABRANGENTE: UMA ANÁLISE EMPÍRICA DA VOLATILIDADE 1

\title{
NET INCOME VERSUS COMPREHENSIVE INCOME: AN EMPIRICAL ANALYSIS OF VOLATILITY
}

\section{GANANCIA NETA VERSUS GANANCIA INTEGRAL: UN ANÁLISIS EMPÍRICO DE LA VOLATILIDAD}

\author{
Laura Edith Taboada Pinheiro \\ Doutora em Contabilidade e Finanças pela Universidad de Zaragoza - Espanha \\ Professora do Programa de Pós-Graduação em Ciências Contábeis \\ da Universidade Federal de Minas Gerais (UFMG) \\ Endereço: Av. Antônio Carlos, 6.627, Pampulha \\ CEP: 31270-901 - Belo Horizonte/MG - Brasil \\ E-mail: Itaboada@face.ufmg.br \\ Telefone: (31) 34097271 \\ Rodney Pereira de Macedo \\ Mestre em Ciências Contábeis pela Universidade Federal de Minas Gerais \\ Endereço: Av. Antônio Carlos, 6.627, Pampulha \\ CEP: 31270-901 - Belo Horizonte/MG - Brasil \\ E-mail: rodney.macedo@bcb.gov.br \\ Telefone: (31) 34097271 \\ Adriana Giarola Vilamaior \\ Mestre em Ciências Contábeis pela Universidade Federal de Minas Gerais \\ Endereço: Av. Antônio Carlos, 6.627, Pampulha \\ CEP 31270-901 - Belo Horizonte/MG - Brasil \\ E-mail: avilamaior@bol.com.br \\ Telefone: (31) 34097271
}

\section{RESUMO}

O contínuo processo para melhor demonstrar a situação patrimonial das empresas culminou na obrigatoriedade da evidenciação do demonstrativo do Resultado Abrangente nos EUA, em 1997. Contrariando teóricos contábeis em alguns pontos, o FASB determinou que certas

\footnotetext{
1 Artigo recebido em 29.10.2011. Revisado por pares em 15.01.2012. Reformulado em 23.04.2012. Recomendado para publicação em 25.04.2012 por Ilse Maria Beuren (Editora). Publicado em 31.12.2012. Organização responsável pelo periódico: FURB.
} 
variações patrimoniais fossem registradas no Patrimônio Líquido, compondo o Resultado Abrangente, em detrimento do reconhecimento no resultado do exercício. Essa postura foi justificada pela volatilidade que certas variações patrimoniais causariam no lucro líquido das empresas. Dada a obrigatoriedade de evidenciação do resultado abrangente no Brasil a partir do exercício encerrado em 31 de dezembro de 2010, este artigo analisa hipotética e empiricamente a volatilidade que os Outros Resultados Abrangentes causariam, caso fossem registrados no resultado do exercício. Utiliza-se de estatística descritiva e do Teste-T: duas amostras em par para médias a fim de analisar 21 empresas brasileiras que divulgaram informações contábeis na NYSE, relativas aos exercícios de 2003 a 2007. Os resultados obtidos por meio da estatística descritiva demonstram que o eventual reconhecimento dos Outros Resultados Abrangentes no resultado causaria maior volatilidade no lucro líquido dessas empresas, sem tendência definida, no sentido de aumentá-lo ou diminuí-lo. A conversão das demonstrações contábeis de investimentos no exterior é o item que mais colabora para tal volatilidade. Já o resultado obtido por meio do Teste-T não rejeitou a hipótese nula, mostrando que não há diferença estatisticamente significativa entre as variáveis volatilidade do Resultado Líquido e volatilidade do Resultado Abrangente.

Palavras-chave: Lucro Abrangente. Lucro Líquido. Volatilidade. Resultado Abrangente.

\section{ABSTRACT}

The ongoing process to better demonstrate the financial position of the companies culminated in compulsory disclosure of the comprehensive income statement in the USA in 1997. Contrary to accounting theorists in some points, FASB determined that certain financial changes were recorded in Equity, composing the Comprehensive Income, to the detriment of recognition in the net income. This stance was justified by the volatility that would cause certain variations in net income of companies. Given the requirement of comprehensive income disclosure in Brazil from the year ended on December 31, 2010, this work analyzes hypothetical and empirically the volatility that Other Comprehensive Income would cause if they were registered in the net income. Descriptive statistics and T-Test were used: two combined samples for means to analyze 21 Brazilian companies that disclosed accounting information in NYSE, for the financial years from 2003 to 2007. The results obtained by means of descriptive statistics show that the possible recognition of Other Comprehensive Income in the net income would cause greater volatility in net income of those companies, without trend set to increase or decrease it. The conversion of the financial statements of overseas investments is the item that most collaborates to this volatility. The result obtained by the T-test did not reject the null hypothesis, showing no statistically significant difference between the variables Net Income volatility and Comprehensive Income volatility.

Keywords: Comprehensive Profit. Net Profit. Volatility. Comprehensive Income.

\section{RESUMEN}

El proceso continuo para demonstrar mejor la situación patrimonial de las empresas culminó en la obligatoriedad de la divulgación del estado de Resultado Integral en los EUA en 1997. Contrariando teóricos contables en algunos puntos, el FASB determinó que ciertas variaciones patrimoniales fuesen registradas en el Patrimonio Neto, componiendo el Resultado Integral, en detrimento del reconocimiento en el resultado del ejercicio. Esa postura fue justificada por la volatilidad que ciertas variaciones patrimoniales causarían en la ganancia neta de las empresas. Dada la obligatoriedad de evidenciar el resultado integral 
en Brasil a partir del ejercicio finalizado el 31 de diciembre de 2010, este trabajo analiza hipotética y empíricamente la volatilidad que los Otros Resultados Integrales causarían, caso fuesen registrados en el resultado del ejercicio. Se utilizó estadística descriptiva y el Test-T: dos muestras en par para medias para analizar 21 empresas brasileñas que divulgaron informaciones contables en la NYSE, relativas a los ejercicios de 2003 a 2007. Los resultados obtenidos a través de la estadística descriptiva demuestran que el eventual reconocimiento de los Otros Resultados Integrales en el resultado causaría mayor volatilidad en la ganancia neta de esas empresas, sin tendencia definida, en el sentido de aumentarla o disminuirla. La conversión de los estados contables de inversiones en el exterior es el ítem que más colabora para tal volatilidad. Ya el resultado obtenido por medio del Test-T no rechazó la hipótesis nula, mostrando que no hay diferencia estadísticamente significativa entre las variables volatilidad del Resultado Neto y volatilidad del Resultado Integral.

Palabras clave: Ganancia Integral. Ganancia Neta. Volatilidad. Resultado Integral.

\section{INTRODUÇÃO}

Desde a tese de doutorado de Paton (1922), considerada radical por Hendriksen e Breda (2007), por defender a contabilização de qualquer alteração de valores, em qualquer direção que seja e independentemente do motivo que a tenha causado, não são poucas as polêmicas envolvendo teóricos contábeis e órgãos normativos. Um exemplo dessa polêmica envolveu a normatização da contabilização dos fundos para aposentadoria nos EUA. $\mathrm{O}$ Financial Accounting Standard Board (FASB) fez concessões para permitir a apropriação gradativa no resultado, dos custos com planos de aposentadoria cujos beneficiários já estavam inativos. Para Hendriksen e Breda (2007), o reconhecimento completo e imediato no resultado seria mais virtuoso do ponto de vista da teoria contábil.

Destarte os pontos polêmicos, pesquisadores da ciência contábil têm-se empenhado na busca de alternativas para fornecer aos usuários das demonstrações contábeis informação que reflita a posição financeira das instituições com maior fidedignidade. Nesse sentido, verificase nos normativos contábeis recentemente emitidos no Brasil e no exterior, tendência em reconhecer cada vez mais itens patrimoniais pelo valor justo, em substituição à utilização do custo histórico como base de valor. A contabilização da contrapartida desse procedimento, entretanto, nem sempre é consenso entre teóricos contábeis e órgãos normativos.

Nesse ambiente de discussão e constante busca pela evolução no aprimoramento da informação contábil, o FASB (1997) emitiu o pronunciamento 130 - Reporting comprehensive income, instituindo que alguns ganhos, perdas, receitas e despesas não realizados devem ser registrados em rubrica específica do patrimônio líquido, denominada Outros resultados abrangentes. Hoyle, Schaefer e Doupnik (2007) destacam o trabalho coordenado entre o FASB e o International Accounting Standard Board (IASB), com o fim de alcançarem compatibilidade entre seus normativos. O IASB (2007), em função do projeto conjunto com o FASB, revisou em 2007 a IAS 1 - Presentation of Financial Statement, determinando a evidenciação do resultado abrangente.

O conceito de resultado abrangente ainda é pouco discutido no Brasil e apenas em setembro de 2009, a Comissão de Valores Mobiliários (CVM), por meio da Deliberação 595, aprovou o Pronunciamento Técnico 26 do Comitê de Pronunciamentos Contábeis (CPC), que incorpora a Demonstração do Resultado Abrangente Total no conjunto completo obrigatório de Demonstrações contábeis.

Há estudos que demonstram que padrões contábeis têm poder de influenciar decisões financeiras e de investimentos, quando estes impõem custos às companhias. Pohlmann e 
Alves (2008) destacam o argumento da Monumental Corporation de que investiria mais em debêntures e menos em ações se os ganhos e perdas não realizados em títulos mobiliários fossem incluídos no resultado.

Um dos argumentos dos empresários para a não inclusão de alguns ganhos e perdas não realizados no resultado é que estes causariam volatilidade nos lucros, e que essa volatilidade seria pressuposto para derrubar o preço das ações de suas empresas (STICKNEY; WEIL, 2001).

De acordo com Mota e Fernandes (2004) o estudo da volatilidade tem grande importância na área de finanças, em especial no apreçamento de derivativos e no gerenciamento de risco. A volatilidade é uma medida de risco porque representa uma medida de dispersão dos retornos de um título ou índice de mercado, assim, quanto mais o preço de uma ação varia num período curto de tempo, maior o risco de se ganhar ou perder dinheiro negociando esta ação. No presente estudo a volatilidade é definida como a taxa de variação ou oscilação do resultado.

Nesse sentido, o objetivo deste artigo é analisar a volatilidade no lucro líquido caso nele fossem registradas as variações dos Outros Resultados Abrangentes. Destaca-se que reconhecer tais variações no resultado do período é uma situação hipotética, mas espera-se assim, contribuir para a discussão de um tema polêmico, suscitado por Paton (1922) há quase um século, e que as empresas brasileiras começaram a divulgar para os exercícios encerrados em 31 de dezembro de 2010, face à exigência da CVM.

\section{REFERENCIAL TEÓRICO}

Embora somente com a emissão do Statement of Financial Accounting Standards (SFAS) 130 (1997) o FASB tenha determinado a divulgação do lucro abrangente (ou resultado abrangente), esse conceito remonta ao SFAS 3 (1980), posteriormente substituído pelo SFAS 6 (1985). Em ambos, o lucro abrangente é definido como alterações no patrimônio da empresa em um período, originadas em transações, circunstâncias e outros eventos, exceto investimentos dos proprietários e distribuições para os proprietários. Houve polêmica envolvendo a diferenciação entre Lucro e Lucro Abrangente, que foi esclarecida pelo FASB no SFAS 5 (1984), ao estabelecer que apesar de os dois terem os mesmos componentes (ganhos, perdas, receitas e despesas), alguns desses ganhos e perdas são incluídos somente no lucro abrangente.

No SFAS 87, o FASB explica que ganhos e perdas incluem montantes realizados e não realizados, que podem refletir ajustes em estimativas e alterações reais em valores econômicos. Alguns ganhos em um período podem ser compensados por perdas em outros e vice-versa, dessa forma, não é requerido que eles sejam reconhecidos imediatamente. A parcela não reconhecida no resultado deve ser evidenciada como acréscimo ou decréscimo em "outros resultados abrangentes".

Epstein, Nach e Bragg (2006) observam que o lucro abrangente corresponde a uma noção mais inclusiva de se perceber o desempenho das empresas que o lucro líquido. No lucro abrangente são compreendidas todas as alterações patrimoniais do período, inclusive aquelas não refletidas no lucro líquido, exceto aquelas oriundas de investimentos dos proprietários e as distribuições para os proprietários.

Schroeder e Clark (2003) destacam que ao determinar o reconhecimento de certos itens em lucros abrangentes, o FASB disciplina esse procedimento em bases conceituais seguras, até então inexistentes para o reconhecimento de itens diretamente no patrimônio líquido. Ademais, propiciou mais transparência ao permitir melhor entendimento de informações antes não apresentadas no balanço. Para esses autores, uma motivação para instituir o lucro abrangente pode ter origem nos derivativos e hedges, em função que vários 
deles eram apresentados apenas em notas explicativas.

À época da emissão do SFAS 130 havia grande discussão sobre mensuração e reconhecimento de instrumentos financeiros pelo valor justo. Esse assunto causava tensão entre os membros do FASB. Alguns defendiam a avaliação pelo valor justo, outros se opunham, temendo os efeitos que a volatilidade dos ganhos e perdas nesses instrumentos poderia causar no resultado.

O FASB (1997) cedeu e no SFAS 130 admitiu que embora existisse o conceito All inclusive, ocasionalmente exceções específicas eram permitidas para que a contrapartida de certas alterações em ativos e passivos fosse apresentada no patrimônio, separadamente de acordo com sua natureza, dentro da rubrica denominada "outros resultados abrangentes", ao invés de ser apresentada no lucro líquido.

De acordo com Schroeder e Clark (2003) no conceito All inclusive receitas, despesas, ganhos e perdas reconhecidos durante o período devem ser incluídos no resultado, independentemente de pertencerem ao resultado das operações do período.

Iudícibus e Martins (2007) atribuem a divulgação do resultado abrangente adotada pelo FASB como decorrência do reconhecimento de ativos pelo valor justo em contraposição ao reconhecimento desses ativos pelo custo histórico. Para esses autores, alguns ativos são reconhecidos pelo valor de mercado sem estarem completamente concretizados todos os pressupostos dos princípios contábeis que justificariam o reconhecimento da receita.

Destaca-se ainda que, ao reconhecer, por meio do resultado abrangente, todas as transações que tenham alterado o valor dos ativos líquidos da empresa, a contabilidade atenderia à premissa do modelo de Ohlson (1995), que caracteriza a articulação limpa entre a Demonstração do Resultado do Exercício e o Balanço Patrimonial. Conforme Carvalho e Coelho (2007), a articulação limpa ocorre quando todas as alterações não relacionadas aos proprietários ocorridas em determinado período e registradas no PL houverem transitado pela DRE.

Por outro lado, Dhaliwal, Subramanyam e Trevezant (1999) analisaram o lucro líquido e o lucro abrangente como medidas de resultado e não encontraram evidências claras de que o lucro abrangente está mais fortemente associado com retornos ou menos fortemente associado com o valor de mercado das ações, em relação ao lucro líquido. O ajuste de títulos e valores mobiliários seria o único componente dos outros resultados abrangentes que melhora a associação entre renda e retorno. Conforme esses autores, uma explicação possível para tal fato é que a conversão de moeda estrangeira e os ajustes no passivo com fundo de aposentadoria envolvem estimativas mais subjetivas em seu cálculo.

De fato, a conversão de demonstrações contábeis exige técnicas como a utilização de uma moeda funcional, no caso de atuação de empresas norte-americanas em economias hiperinflacionárias. Baker, Lembke e King (2005) destacam que se não fosse assim, haveria situações em que os valores traduzidos não refletiriam o valor de mercado, tampouco o custo histórico. O FASB considera uma economia hiper-inflacionária quando sua inflação ultrapassa $100 \%$ em um período acumulado de três anos.

O cálculo do passivo com fundos de aposentadoria também é complexo. Além da necessidade de utilização de projeções da expectativa de vida dos participantes do plano, algumas definições não são muito precisas. Para se definir o custo do período com planos de benefício definido, por exemplo, exige-se a identificação do retorno real dos ativos do plano. Contudo, apesar de utilizar o termo retorno real, que para muitos, significa o retorno efetivamente ocorrido, Schroeder e Clark (2003) explicam que o FASB também permite o uso do retorno esperado. Esses autores entendem que reconhecer o retorno real é consistente com o conceito de lucro abrangente.

Não obstante os resultados da pesquisa de Dhaliwal, Subramanyam e Trevezant (1999), a evidenciação do resultado abrangente continua sendo exigida pelo FASB. Não há 
determinação expressa de formato ou em qual demonstração financeira o lucro abrangente deve ser apresentado, mas incentiva-se que os outros resultados abrangentes sejam evidenciados logo após o lucro líquido, na demonstração que apresentar o resultado das operações. Opcionalmente, permite-se que as empresas divulguem o lucro abrangente em demonstrativo separado dos demais, desde que se inicie com o lucro líquido.

Dentre os ganhos e perdas não realizados, o Quadro 1 resume os itens a serem incluídos no resultado abrangente, conforme determinação do FASB.

\begin{tabular}{|l|l|}
\hline \multicolumn{1}{|c|}{ Itens } & \multicolumn{1}{c|}{ Descrição } \\
\hline $\begin{array}{l}\text { Fundos de } \\
\text { aposentadoria }\end{array}$ & $\begin{array}{l}\text { Custo devido pelo serviço prestado em períodos anteriores ao da implementação ou } \\
\text { modificação do plano, quando todos ou quase todos os participantes estão aposentados. }\end{array}$ \\
\cline { 2 - 2 } & Ganhos perdas atuariais nos planos de benefício definido. \\
\hline $\begin{array}{l}\text { Conversão de } \\
\text { demonstrações } \\
\text { contábeis }\end{array}$ & $\begin{array}{l}\text { Ganhos e perdas não realizados, originados na conversão de demonstrações contábeis em } \\
\text { moeda estrangeira. }\end{array}$ \\
\hline $\begin{array}{l}\text { Títulos e valores } \\
\text { mobiliários }\end{array}$ & $\begin{array}{l}\text { Ganhos e perdas não realizados em títulos disponíveis para venda, avaliados pelo valor } \\
\text { justo. }\end{array}$ \\
\hline Hedge & $\begin{array}{l}\text { Parcela efetiva do ganho ou perda no hedge de fluxo de caixa; parcela efetiva do ganho } \\
\text { ou perda do hedge da variação cambial; e o ganho ou perda em hedge de investimento } \\
\text { líquido em operações no exterior, como parte dos ajustes na tradução, na extensão em } \\
\text { que o instrumento é efetivo como hedge da variação cambial. }\end{array}$ \\
\hline
\end{tabular}

Quadro 1 - Composição dos Outros Resultados Abrangentes

Fonte: Elaboração própria a partir dos pronunciamentos do FASB.

Ressalta-se que além dos itens exigidos pelo FASB, o IASB recomenda a evidenciação do Reavaluation Surplus (Reserva de reavaliação), em outros resultados abrangentes.

\section{PROCEDIMENTOS METODOLÓGICOS}

Esta pesquisa se caracteriza como descritiva, que segundo Cervo e Bervian (1996), é a pesquisa que observa, registra, analisa e correlaciona fatos ou fenômenos do mundo físico e especialmente do mundo humano (variáveis), sem manipulá-los. Gil (1999) complementa que a pesquisa descritiva descreve característica de uma determinada população ou fenômeno ou o estabelecimento de relações entre variáveis. Lucro Líquido e Lucro Abrangente são as duas variáveis analisadas neste trabalho, com o objetivo de verificar o nível de volatilidade que os outros resultados abrangentes, atualmente registrados na segunda variável, causariam na primeira, caso nela fossem registrados.

A estratégia utilizada na pesquisa é classificada como documental. Martins e Theóphilo (2007) destacam que a utilização de documentos como fonte de dados, informações e evidências caracteriza uma pesquisa como documental, desde que as fontes sejam primárias. Godoy (1995) afirma que o exame de materiais de natureza diversa, que ainda não receberam um tratamento analítico, ou que podem ser reexaminados, buscando-se novas e/ou interpretações complementares, constitui o que se denomina pesquisa documental.

A análise dos dados selecionados foi feita de forma quantitativa. Martins e Theóphilo (2007) recomendam avaliação quantitativa para organizar, caracterizar e interpretar dados numéricos. Segundo Richardson (1999), essa análise caracteriza-se pelo emprego da quantificação na coleta de informações, no tratamento das informações por meio de técnicas estatísticas, desde as mais simples até as mais complexas.

\subsection{Amostra e Período Analisado}

Foram analisados neste artigo os itens evidenciados em Outros resultados abrangentes, 
extraídos dos relatórios contábeis anuais das empresas brasileiras que participam do mercado da NYSE, portanto, empresas que publicaram em United States Generally Accepted Accounting Principles (US GAAP). As demonstrações contábeis analisadas referem-se aos exercícios de 2003 a 2007. Foram coletados dados referentes ao Lucro Líquido e às variações de capital, não pertencentes aos proprietários. A amostra compreende as vinte e uma empresas listadas no Quadro 2. A população contempla trinta empresas, contudo, nove foram excluídas por serem empresas do setor financeiro, setor altamente regulamentado e que deve observar regras específicas, ou por não terem apresentado todos os relatórios em todos os períodos analisados.

A escolha das empresas brasileiras que possuem ações listadas nos Estados Unidos deveu-se ao fato de contar com um período maior de divulgação dos outros resultados abrangentes, já que no Brasil somente passou a ser exigido a partir das demonstrações contábeis encerradas em 31 de dezembro de 2010.

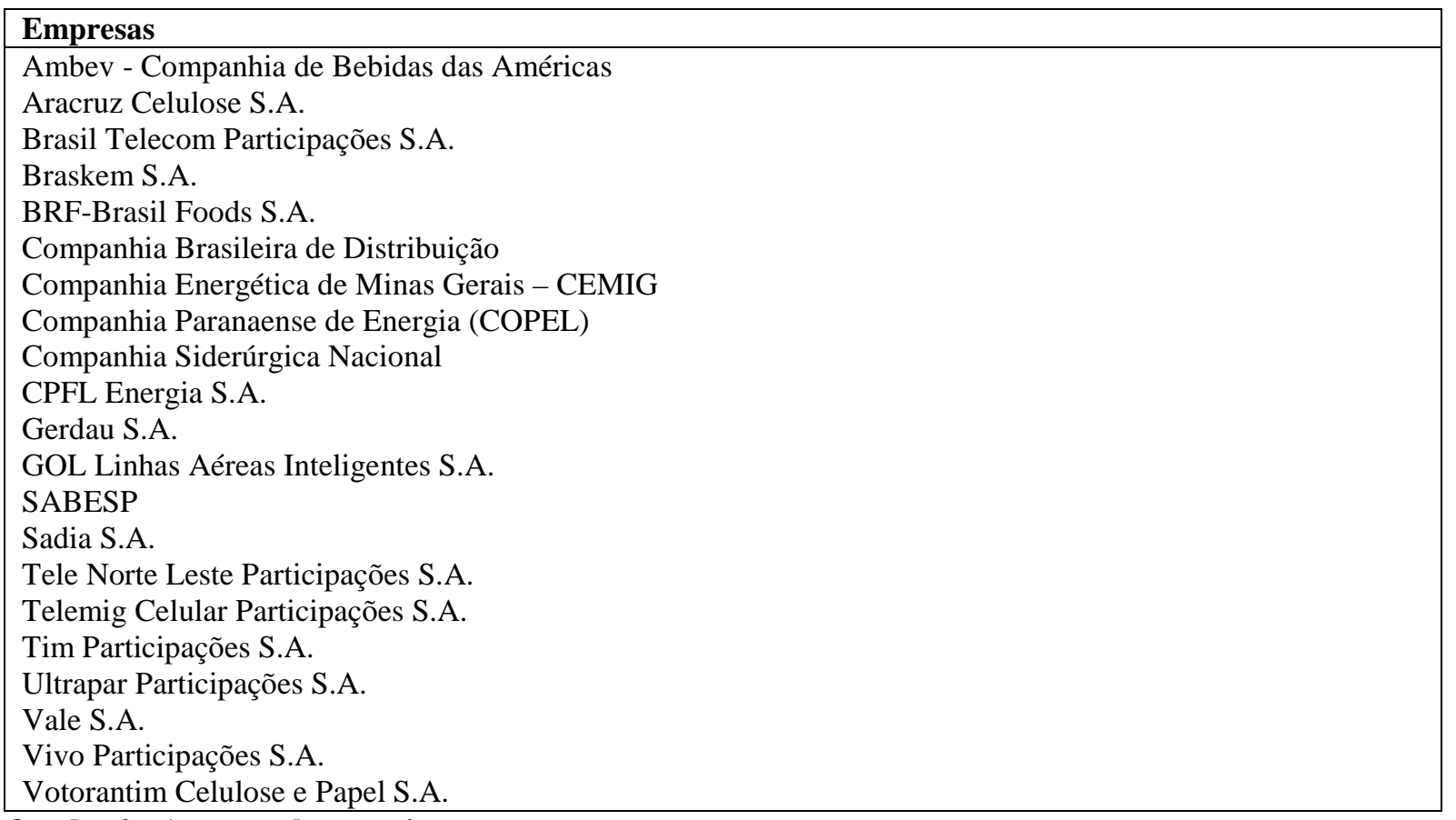

Quadro 2 - Amostra da pesquisa

Fonte: Elaboração própria a partir de dados da NYSE.

\subsection{Descrição do Modelo}

Este artigo pretende analisar a volatilidade no lucro líquido, caso nele fossem incluídas as variações registradas no Patrimônio Líquido, em “outros resultados abrangentes". Para tal, utilizou-se as fórmulas que seguem:

$\mathrm{LA}_{\mathrm{it}}=\mathrm{LL}_{\mathrm{it}}+\mathrm{ORA}_{\mathrm{it}}$

Onde:

LA - Lucro abrangente da empresa i no ano $t$

LL - Lucro líquido da empresa i no ano $t$

ORA - Outros resultados abrangentes da empresa i no ano $t$

Essa fórmula foi aplicada entre os períodos de 2003 a 2007, nos resultados das empresas analisadas. Após esse cálculo, comparou-se o Lucro Líquido de um período com o Lucro Líquido do período subsequente, ponderado pelo Ativo total das empresas de cada ano. 
Esse mesmo procedimento foi adotado para a comparação do Resultado Abrangente entre o período anterior e o subsequente, de 2003 a 2007. Em seguida, realizou-se a subtração entre a volatilidade do Lucro Líquido e a volatilidade do Resultado Abrangente entre os períodos pesquisados. Formalmente, o estudo foi assim estabelecido:

$\mathrm{VLL}_{\mathrm{it}}=\left\{\left[\left(\mathrm{LL}_{\mathrm{i} t} / \mathrm{AT}_{\mathrm{it}}\right)-\left(\mathrm{LL}_{\mathrm{i}(\mathrm{t}-1)} / \mathrm{AT}_{\mathrm{i}(\mathrm{t}-1)}\right)\right] /\left(\mathrm{LL}_{\mathrm{i}(\mathrm{t}-1)} / \mathrm{AT}_{\mathrm{i}(\mathrm{t}-1)}\right)\right\} \times 100$

Onde:

$\mathrm{VLL}_{\mathrm{it}}=$ Variação do lucro líquido da empresa i no ano t, em relação ao ano t-1;

$\mathrm{LL}_{\mathrm{it}}=$ Lucro líquido da empresa i no ano t;

$\mathrm{LL}_{\mathrm{i}(\mathrm{t}-1)}=$ Lucro líquido da empresa i no ano anterior, $\mathrm{t}-1$

$\mathrm{AT}_{\text {it }}=$ Ativo Total da empresa i no ano t;

$\mathrm{AT}_{\mathrm{i}(\mathrm{t}-1)}=$ Ativo Total da empresa i no ano anterior, $\mathrm{t}-1$.

VLAit $=\left\{\left[\left(\mathrm{LA}_{\mathrm{it}} / \mathrm{AT}_{\mathrm{it}}\right)-\left(\mathrm{LA}_{\mathrm{i}(\mathrm{t}-1)} / \mathrm{AT}_{\mathrm{i}(\mathrm{t}-1)}\right)\right] /\left(\mathrm{LAi}_{(\mathrm{t}-1) /} \mathrm{AT}_{\mathrm{i}(\mathrm{t}-1)}\right)\right\} \times 100$

Onde:

$\mathrm{VLA}_{\text {it }}=$ Variação do lucro abrangente da empresa i no ano t, em relação ao ano t-1;

$\mathrm{LA}_{\mathrm{it}}=$ Lucro abrangente da empresa i no ano $\mathrm{t}$;

$\mathrm{LA}_{\mathrm{i}(\mathrm{t}-1)}=$ Lucro abrangente da empresa i no ano anterior, $\mathrm{t}-1$.

$\mathrm{AT}_{\text {it }}=$ Ativo Total da empresa i no ano t;

$\mathrm{AT}_{\mathrm{i}(\mathrm{t}-1)}=$ Ativo Total da empresa i no ano anterior, $\mathrm{t}-1$.

$\mathrm{V}_{\text {it }}\left(\mathrm{VLA}_{\mathrm{it}} \mathrm{VLL}_{\mathrm{it}}\right)=\mathrm{VLA}_{\mathrm{it}}-\mathrm{VLL}_{\mathrm{it}}$

Onde:

$\mathrm{V}_{\text {it }}\left(\mathrm{VLA}_{\mathrm{it}} \mathrm{VLL}_{\mathrm{it}}\right)=$ Variação entre a Variação do Lucro Abrangente i no ano t, em relação ao ano t-1 e a Variação do lucro líquido da empresa i no ano t, em relação ao ano t-1, da empresa i no ano t.

Os dados resultantes foram analisados, primeiramente, por meio de estatísticas descritivas, que mostraram tendência pelas medidas da média, do desvio padrão e da variância. Também foi realizada uma análise dos componentes do Lucro Abrangente nas quatro empresas que apresentaram maior variação na $\mathrm{V}_{\text {it }}\left(\mathrm{VLA}_{\mathrm{it}} \mathrm{VLL}_{\mathrm{it}}\right)$.

Os dados também foram analisados pela ferramenta do Teste-T: duas amostras em par para médias, obtida por meio do uso do software Microsoft Office Excel 2003. Essa ferramenta tem como objetivo apurar se os valores de uma amostra são, em média, iguais aos valores de outra. Portanto pretendeu-se verificar se a média das diferenças entre as amostras das variáveis $V_{L L}$ e $V_{i t} A_{i t}$ diferem significativamente ou não de zero.

Com nível de confiança de $5 \%$ e grau de liberdade de 20, a hipótese nula é de que a diferença de médias é igual a zero: $\mathrm{H}_{0}: m d=0$.

\section{ANÁLISE DOS RESULTADOS}

Antes de se analisar a diferença entre a variação do Lucro Abrangente e a variação do Lucro Líquido, apresenta-se uma análise individual dos dados obtidos em cada medida. A Tabela 1 demonstra os resultados da estatística descritiva e a variação do lucro líquido nos períodos estudados. 
Tabela 1 - Estatísticas descritivas da $V L L_{i t}$

\begin{tabular}{lccccc}
\hline Medidas & $\mathbf{2 0 0 7}$ & $\mathbf{2 0 0 6}$ & $\mathbf{2 0 0 5}$ & $\mathbf{2 0 0 4}$ & $\mathbf{2 0 0 3}$ \\
\hline Média & $61 \%$ & $-11 \%$ & $27 \%$ & $14 \%$ & $-13 \%$ \\
Erro padrão & 0,86 & 0,20 & 0,13 & 0,30 & 6,22 \\
Desvio padrão & 3,94 & 0,92 & 0,61 & 1,36 & 28,50 \\
Variância da amostra & 15,55 & 0,85 & 0,38 & 1,85 & 811,98 \\
\hline
\end{tabular}

Fonte: Elaboração própria.

Observa-se que, em média, houve variação no Lucro Líquido das empresas em relação ao Lucro Líquido do ano anterior de 61\%, em 2007. Ressalta-se que a média obtida nos demais períodos apresenta resultados díspares (positivo ou negativo), não havendo um padrão definido.

O desvio padrão apresenta valores também bastante distintos, sendo de 0,61 em 2005 e de 28,5 em 2003. Esses dois números representam os extremos dos valores obtidos para essa medida. Isso significa que em 2003, os valores extremos obtidos na variação do lucro líquido são bem mais distantes da média dessa variação que nos demais períodos.

A Tabela 2 demonstra a análise da variação no Lucro Abrangente das empresas, considerando sua análise em relação ao Lucro Abrangente do período anterior.

Tabela 2 - Estatísticas descritivas da VLA

\begin{tabular}{lccccc}
\hline Medidas & $\mathbf{2 0 0 7}$ & $\mathbf{2 0 0 6}$ & $\mathbf{2 0 0 5}$ & $\mathbf{2 0 0 4}$ & $\mathbf{2 0 0 3}$ \\
\hline Média & $83 \%$ & $-12 \%$ & $77 \%$ & $1100 \%$ & $438 \%$ \\
Erro padrão & 0,79 & 0,24 & 0,56 & 10,71 & 3,31 \\
Desvio padrão & 3,64 & 1,11 & 2,55 & 49,08 & 15,18 \\
Variância da amostra & 13,24 & 1,23 & 6,49 & 2408,53 & 230,35 \\
\hline
\end{tabular}

Fonte: Elaboração própria.

Observa-se que na maioria dos valores obtidos na Tabela 2, a média apresentou-se maior que a apresentada na Tabela 1, quando foi analisada a variação do Lucro Líquido. Essa constatação permite inferir que há maior volatilidade entre os valores do Lucro Abrangente. Esses dados amostrais também apresentaram desvios padrões bastante diferentes, sendo de 49,08 em 2004 e de 1,11 em 2006. Houve mudança entre os períodos que apresentaram maior e menor valor de desvio padrão. Para a VLLit foi o ano 2003, já para a VLA it foi 2004 que apresentou maior desvio padrão. Já o menor desvio padrão foi do ano de 2006 na análise do $\mathrm{VLA}_{\text {it }}$ e do ano de 2005 para VLL it. Isso também demonstra que existe diferença entre os valores dos resultados, denominados limpos (CARVALHO; COELHO, 2007) e os valores de Lucro Líquido.

Considerando a amostra das vinte e uma empresas brasileiras que negociaram ações na NYSE relativos aos exercícios de 2003 a 2007, os componentes dos outros resultados abrangentes foram analisados individualmente, para as quatro empresas que apresentaram grande volatilidade no Lucro Abrangente. Os resultados são apresentados na Tabela 3.

Observa-se na Tabela 3 que a Conversão de demonstrações contábeis foi o componente de Outros Resultados Abrangentes que mais contribuiu para a volatilidade do Lucro Abrangente nas quatro empresas. Contudo esse componente se apresenta apenas em empresas que possuem investimentos em outras sociedades localizadas no exterior. Como era de se esperar como tendência, a observância dos preceitos da Deliberação 595/09 da CVM implicará em menor volatilidade no resultado abrangente das empresas que possuam investimentos apenas no Brasil. 
Tabela 3 - Porcentagem da formação dos Componentes de Outros Resultados Abrangentes

\begin{tabular}{|c|c|c|c|c|c|}
\hline Componentes de ORA & 2007 & 2006 & 2005 & 2004 & 2003 \\
\hline \multicolumn{6}{|l|}{ Companhia Paran. de Energia (COPEL) } \\
\hline Títulos e valores mobiliários & $0 \%$ & $0 \%$ & $0 \%$ & $0 \%$ & $0 \%$ \\
\hline Hedge & $0 \%$ & $0 \%$ & $0 \%$ & $0 \%$ & $0 \%$ \\
\hline Fundos de aposentadoria & $0 \%$ & $0 \%$ & $0 \%$ & $152 \%$ & $152 \%$ \\
\hline Conversão de demonstrações contábeis & $100 \%$ & $0 \%$ & $0 \%$ & $-52 \%$ & $-52 \%$ \\
\hline \multicolumn{6}{|l|}{ Gerdau S.A. } \\
\hline Títulos e valores mobiliários & $0.88 \%$ & $0.00 \%$ & $0.00 \%$ & $0.00 \%$ & $0.00 \%$ \\
\hline Hedge & $0.00 \%$ & $0.00 \%$ & $0.00 \%$ & $0.00 \%$ & $1.52 \%$ \\
\hline Fundos de aposentadoria & $5.16 \%$ & $6.30 \%$ & $-8.70 \%$ & $-2.32 \%$ & $3.16 \%$ \\
\hline Conversão de demonstrações contábeis & $93.96 \%$ & $93.70 \%$ & $108.70 \%$ & $102.32 \%$ & $95.31 \%$ \\
\hline \multicolumn{6}{|l|}{ Vale S.A. } \\
\hline Títulos e valores mobiliários & $-2.26 \%$ & $11.38 \%$ & $3.06 \%$ & $3.49 \%$ & $9.14 \%$ \\
\hline Hedge & $1.09 \%$ & $0.00 \%$ & $0.00 \%$ & $0.00 \%$ & $0.00 \%$ \\
\hline Fundos de aposentadoria & $-10.46 \%$ & $-8.46 \%$ & $0.00 \%$ & $0.00 \%$ & $0.00 \%$ \\
\hline Conversão de demonstrações contábeis & $111.62 \%$ & $97.08 \%$ & $96.94 \%$ & $96.51 \%$ & $90.86 \%$ \\
\hline \multicolumn{6}{|l|}{ Votorantim Celulose e Papel S.A. } \\
\hline Títulos e valores mobiliários & $0.00 \%$ & $0.00 \%$ & $5.76 \%$ & $0.00 \%$ & $0.00 \%$ \\
\hline Hedge & $0.00 \%$ & $0.00 \%$ & $0.00 \%$ & $0.00 \%$ & $0.00 \%$ \\
\hline Fundos de aposentadoria & $0.00 \%$ & $0.00 \%$ & $0.00 \%$ & $0.00 \%$ & $0.00 \%$ \\
\hline Conversão de demonstrações contábeis & $100.00 \%$ & $100.00 \%$ & $94.24 \%$ & $100.00 \%$ & $100.00 \%$ \\
\hline
\end{tabular}

Fonte: Elaboração própria.

Também, pretendeu se constatar a existência de diferença entre VLA $_{i t}$ e VLL it $_{\text {it }}$ utilizando o Teste-t para duas amostras em par para médias, como se observa na Tabela 4.

Tabela 4- Teste-t: duas amostras em par para médias das variáveis $\mathrm{VLA}_{\mathrm{it}}$ e $\mathrm{VLL}_{\mathrm{it}}$

\begin{tabular}{|c|c|c|c|c|c|}
\hline \multirow[b]{2}{*}{ Anos } & \multicolumn{2}{|c|}{ Média } & \multirow{2}{*}{$\begin{array}{l}\text { Correlação de } \\
\text { Pearson }\end{array}$} & \multirow[b]{2}{*}{ Stat $\mathrm{t}$} & \multirow{2}{*}{$\begin{array}{l}\text { t crítico } \\
\text { bi-caudal }\end{array}$} \\
\hline & VLL $_{i t}$ & $\mathrm{VLA}_{\mathrm{it}}$ & & & \\
\hline 2007 & $61,4 \%$ & $83,0 \%$ & 0,97 & $-1,02$ & \\
\hline 2006 & $-11,3 \%$ & $-12,0 \%$ & 0,96 & 0,09 & \\
\hline 2005 & $26,7 \%$ & $77,1 \%$ & 0,18 & $-0,92$ & 2,09 \\
\hline 2004 & $13,6 \%$ & $1099,9 \%$ & 0,13 & $-1,02$ & \\
\hline 2003 & $-13,1 \%$ & $437,7 \%$ & 0,52 & $-0,85$ & \\
\hline
\end{tabular}

Fonte: Elaboração própria.

As extremidades das curvas da diferença das médias entre as variáveis Variação do lucro líquido da empresa i no ano t, em relação ao ano t-1 (VLL $\left.L_{i t}\right)$ e Variação do lucro abrangente da empresa i no ano t, em relação ao ano t-1 (VLA it $_{\text {) }}$ são -2,09 e 2,09, com 95\% de confiança e 20 graus de liberdade. Sendo assim, verifica-se que as Estatísticas t (Stat t) dos anos de 2003 a 2007, encontram-se dentro da região de aceitação. Portanto, não rejeita a Hipótese $\mathrm{H}_{0}$ de que não há diferença significativa entre as variáveis $\mathrm{VLL}_{i t}$ e VLA $\mathrm{A}_{\mathrm{it}}$, ou seja, a amostra não fornece evidência estatística de diferença entre as variáveis. É importante ressaltar que os Coeficientes de Correlação de Pearson de 2005 e 2004 apresentaram se mais baixos, ou seja, fraca correlação, que os outros anos da análise. Já nos anos de 2006 e 2007 esse coeficiente apresentou-se maior que 0,90 , ou seja, forte correlação entre os dados.

\section{CONCLUSÕES}

O contínuo processo em busca de melhor evidenciação das informações contábeis 
culminou na obrigatoriedade, em 1997, da evidenciação do Resultado Abrangente, de acordo com os princípios do FASB. Esse processo foi marcado por polêmicas entre este órgão normatizador, teóricos contábeis e empresários. Entre os teóricos, a maioria era favorável à evidenciação de certas variações patrimoniais no Lucro Líquido, enquanto os empresários defendiam que tais variações causariam volatilidade no lucro de suas empresas, e consequentemente, volatilidade no preço das ações dessas empresas.

O FASB cedeu em alguns pontos e determinou que certas variações patrimoniais fossem registradas no Patrimônio Líquido, compondo o Resultado Abrangente. A transição para o Lucro Líquido se dá no período da realização. Para Epstein, Nach e Bragg (2006), o Lucro Abrangente demonstra melhor o desempenho das empresas que o Lucro Líquido porque inclui todas as alterações patrimoniais do período, exceto aquelas oriundas de investimentos dos proprietários e as distribuições para os proprietários. Por outro lado, Dhaliwal, Subramanyam e Trevezant (1999) não encontraram evidências claras de que o lucro abrangente está mais fortemente associado com retornos ou menos fortemente associado com o valor de mercado das ações, em relação ao lucro líquido.

Dada a polêmica envolvendo a volatilidade que o eventual registro dos Outros Resultados Abrangentes causaria no Lucro Líquido, caso neste fossem registrados, e a exigência da divulgação do resultado abrangente no Brasil a partir dos exercícios encerrados em 31 de dezembro de 2010, neste trabalho pretendeu-se analisar a volatilidade no lucro líquido caso nele fossem registradas as variações dos Outros Resultados Abrangentes.

Os resultados obtidos por meio da aplicação de estatística descritiva no Lucro Líquido e no Resultado Abrangente de vinte e uma empresas brasileiras que negociam ações na NYSE confirmam a hipótese da alta volatilidade. Em todas as análises efetuadas, verificou-se volatilidade, sem tendência definida no sentido de aumento ou diminuição do Lucro. Tal fato comprova o argumento suscitado pelo próprio FASB para não determinar o reconhecimento imediato de certas variações relacionadas a custos com fundos de aposentadoria. Alguns ganhos de um período poderiam ser compensados por perdas em outros, e vice-versa. Outra conclusão deste trabalho, feita por meio da estatística descritiva é que a conversão das demonstrações contábeis de investimentos no exterior foi o item que mais contribuiu para a volatilidade do Resultado Abrangente. Como esse item está presente apenas nos relatórios contábeis de empresas que possuem investimentos em outras sociedades localizadas no exterior, há menor volatilidade no resultado abrangente de empresas que possuam investimentos somente no Brasil.

Porém, a análise feita por meio da ferramenta Teste-T para duas amostras em par para médias, permitiu verificar que a diferença entre a volatilidade do Lucro Líquido e a volatilidade dos Resultados abrangentes não é estatisticamente significativa.

Diante dos resultados, espera-se ter contribuído para o aumento da discussão acadêmica desse tema no Brasil. Visando ampliar a discussão sobre essa nova demonstração contábil introduzida recentemente no Brasil, sugere-se a realização de novos estudos que analisem a divulgação do resultado abrangente a partir do exercício de 2010 no mercado brasileiro.

\section{REFERÊNCIAS}

BAKER, R. E.; LEMBKE, V. C.; KING, T. E. Advanced financial accounting. Boston: McGrawHill/Irwin, 2005.

CARVALHO, L. N; COELHO, A. C. Análise conceitual de lucro abrangente e lucro operacional corrente: Evidências no setor financeiro brasileiro. Brazilian Business Review BBR, Vitória, v. 4, n. 2, p. 119-139, mai./ago. 2007. 
CERVO, A. L.; BERVIAN, P. A. Metodologia científica. São Paulo: Makron Books, 1996.

COMISSÃO DE VALORES MOBILIÁRIOS - CVM. Deliberação $\mathbf{n}^{\circ} \mathbf{5 9 5 / 0 9}$, de 15 de setembro de 2009. Aprova o Pronunciamento Técnico CPC 26 do Comitê de Pronunciamentos Contábeis, que trata de apresentação das demonstrações contábeis. Disponível em: 〈http://www.cvm.gov.br〉. Acesso em: 20 fev. 2010.

COMITÊ DE PRONUNCIAMENTOS CONTÁBEIS - CPC. Pronunciamento técnico CPC 26: Apresentação das Demonstrações Contábeis. Disponível em: <http://www.cpc.org.br/pdf/ CPC\%2026_2010.pdf>. Acesso em: 27 fev. 2010.

COMITÊ DE PRONUNCIAMENTOS CONTÁBEIS - CPC. Pronunciamento técnico CPC 02(R1): Efeitos das mudanças nas taxas de câmbio e conversão das demonstrações contábeis. Disponível em: <http://www.cpc.org.br/pdf/CPC\%2026_2010.pdf>. Acesso em: 27 fev. 2010.

DHALIWAL, D; SUBRAMANYAM, K. R.; TREVEZANT, R. Is comprehensive income superior to net income as a measure of firm performance? Journal of Accounting and Economics, Los Angeles, v. 26, p. 43-67, jan. 1999. http://dx.doi.org/10.1016/S01654101(98)00033-0

EPSTEIN, B. J.; NACH, R.; BRAGG, S. M. GAAP Interpretation and Application of Generally Accepted Accounting Principles. New Jersey: John Wiley \& Sons, 2006.

FINANCIAL ACCOUNTING STANDARD BOARD - FASB. Statement of Financial Accounting Standards - SFAS 3: Elements of financial statements of business enterprises, Dec. 1980. Disponível em: <http://www.fasb.org>. Acesso em: 01 jul. 2009.

FINANCIAL ACCOUNTING STANDARD BOARD - FASB. Statement of Financial Accounting Standards - SFAS 5: Recognition and measurement in financial statements of business enterprises, Dec. 1984. Disponível em: 〈http://www.fasb.org>. Acesso em: 01 jul. 2009.

FINANCIAL ACCOUNTING STANDARD BOARD - FASB. Statement of Financial Accounting Standards - SFAS 6: Elements of financial statements - a replacement of FASB concepts statement $n^{\circ} .3$ (incorporating an amendment of FASB concepts statement $n^{0} .2$ ), Dec. 1985. Disponível em: <http://www.fasb.org>. Acesso em: 01 jul. 2009.

FINANCIAL ACCOUNTING STANDARD BOARD - FASB. Statement of Financial Accounting Standards - SFAS 052: Foreign Currency Translation, Dec. 1981. Disponível em: 〈http://www.fasb.org>. Acesso em: 01 jul. 2009.

FINANCIAL ACCOUNTING STANDARD BOARD - FASB. Statement of Financial Accounting Standards - SFAS 087: Employers' Accounting for Pensions, Dec. 1985. Disponível em: <http://www.fasb.org>. Acesso em: 01 jul. 2009.

FINANCIAL ACCOUNTING STANDARD BOARD - FASB. Statement of Financial Accounting Standards - SFAS 130: Reporting Comprehensive Income, Jun. 1997. Disponível em: <http://www.fasb.org>. Acesso em: 01 jul. 2009.

GIL, A. C. Métodos e técnicas de pesquisa social. São Paulo: Atlas, 1999.

GODOY, A. Introdução à pesquisa qualitativa e suas possibilidade. Revista de Administração de Empresas, São Paulo, v. 35, n. 2, p. 57-63, mar./abr. 1995. http://dx.doi.org/10.1590/S0034-75901995000200008

HENDRIKSEN, E. S.; VAN BREDA, M. F. Teoria da contabilidade. São Paulo: Atlas, 2007. 
HOYLE, J. B.; SCHAEFER, T. F.; DOUPNIK, T. S. Advanced accounting. Boston: McGrawHill/Irwin, 2007.

INTERNATIONAL ACCOUNTING STANDARD BOARD - IASB. Presentation of Financial Statement - IAS 1, Set. 2007. Disponível em: <http://www.iasb.org/ Current+Projects/IASB+Projects/Financial+Statement+Presentation/Financial+Statement+Pre sentation.htm>. Acesso em: 27 fev. 2010.

IUDÍCIBUS, S.; MARTINS, E. Uma investigação e uma proposição sobre o conceito e o uso do valor justo. Revista Contabilidade \& Finanças, São Paulo, edição 30 anos de doutorado, p. 9-18, jun. 2007. http://dx.doi.org/10.1590/S1519-70772007000300002.

MARTINS, G. A.; THEÓFILO, C. R. Metodologia da investigação científica para ciências sociais aplicadas. São Paulo: Atlas, 2007.

MOTA, Bernardo de Sá; FERNANDES, Marcelo. Desempenho de estimadores de volatilidade na bolsa de valores de São Paulo. Revista Brasileira de Economia. Rio de Janeiro, v. 58, n. 3, p. 429-448, jul./set. 2004.

NEW YORK STOCK EXCHANGE - NYSE. Disponível em: <http://www.nyse.com/>. Acesso em: 30 set. 2009.

OHLSON, J. A. Earnings, book values, and dividends in equity valuation. Contemporary Accounting Research, v. 11, p. 661-687, 1995. http://dx.doi.org/10.1111/j.19113846.1995.tb00461.x.

PATON, W. A. Accounting Theory: with special reference to the corporate enterprise. New York: Ronad Press, 1922.

POHLMANN, M. C.; ALVES, F. J. S. Regulamentação. In: IUDÍCIBUS, S.; LOPES, A. B. Teoria avançada da contabilidade. São Paulo: Atlas, 2008.

RICHARDSON, R. J. Pesquisa social: métodos e técnicas. São Paulo: Atlas, 1999.

SCHROEDER, R. G.; CLARK, M. W. Accounting theory: text and readings. John Wiley \& Sons, 2003.

STICKNEY, C. P.; WEIL, R. L. Contabilidade financeira: uma introdução aos conceitos, métodos e usos. São Paulo: Atlas, 2001.

U.S. SECURITIES AND EXCHANGE COMMISSION - SEC. Disponível em: <http://www.sec.gov>. Acesso em: 30 set. 2009. 